\title{
A study on episodic memory reconsolidation that tells us more about consolidation
}

\author{
Michael Craig, ${ }^{1,2}$ Christopher Knowles, ${ }^{1}$ Stephanie Hill, ${ }^{1}$ and Michaela Dewar ${ }^{1}$ \\ ${ }^{1}$ Memory Lab, Department of Psychology, School of Social Sciences, Heriot Watt University, Edinburgh EH14 4AS, United Kingdom; \\ ${ }^{2}$ Department of Psychology, Faculty of Health and Life Sciences, Northumbria University, Newcastle upon Tyne NE1 8ST, United \\ Kingdom
}

\begin{abstract}
Awake quiescence immediately after encoding is conducive to episodic memory consolidation. Retrieval can render episodic memories labile again, but reconsolidation can modify and restrengthen them. It remained unknown whether awake quiescence after retrieval supports episodic memory reconsolidation. We sought to examine this question via an object-location memory paradigm. We failed to probe the effect of quiescence on reconsolidation, but we did observe an unforeseen "delayed" effect of quiescence on consolidation. Our findings reveal that the beneficial effect of quiescence on episodic memory consolidation is not restricted to immediately following encoding but can be achieved at a delayed stage and even following a period of task engagement.
\end{abstract}

[Supplemental material is available for this article.]

For labile new memories to be remembered they must be consolidated, that is, strengthened and stabilized, over time (Dudai 2004; Wixted 2004). Extensive research demonstrates that postencoding sleep and awake quiescence (quiet rest) are conducive to human episodic memory consolidation (Clemens et al. 2005; Ferrara et al. 2008; Lahl et al. 2008; Wamsley et al. 2010; Dewar et al. 2012, 2014; Gaskell et al. 2014; Mercer 2015; Brokaw et al. 2016; Craig and Dewar 2018; Craig et al. 2019; Sacripante et al. 2019). Sleep and wakeful rest are hypothesized to support consolidation by providing a state of reduced sensory input and task engagement (Hasselmo 1999; Wixted 2004; Mednick et al. 2011; Dewar et al. 2012, 2014; Craig and Dewar 2018; Craig et al. 2019).

Memories are not destined to remain fixed and unmodifiable once consolidated. An increasing body of evidence suggests that the cueing or retrieval of consolidated memories, for example, via internally or externally generated exposure to learned materials (Wichert et al. 2011; Agren 2014), can return such memories into a labile state (Dudai and Eisenberg 2004; McKenzie and Eichenbaum 2011; Schwabe et al. 2014). These relabilized memories are thought to require a process of "reconsolidation" (Rodriguez et al. 1993; Przybyslawski and Sara 1997) in order to restabilize and persist. Evidence for reconsolidation in humans comes from research demonstrating that memories can be disrupted and/or updated by the application of treatments shortly following their retrieval. This includes (1) the disruption and modification of episodic memories via the presentation of similar/related materials (Loftus 2005; Hupbach et al. 2007), (2) a reduction in the number of traumatic memory intrusions following postretrieval engagement in visuospatial tasks (Deeprose et al. 2012; James et al. 2015; Hagenaars et al. 2017), and (3) the extinction of fear memories and increased forgetting of emotional memories via the administration of pharmaceuticals and electrophysiological stimulation (Cahill et al. 1994; Debiec and Ledoux 2004; Kroes et al. 2014). In all cases, the effect of postretrieval treatment is seen only for memories that are retrieved (e.g., via a memory test or cue) prior to the treatment. Memories that were not retrieved (i.e., controls) were unaf-

Corresponding author: michael2.craig@northumbria.ac.uk Article is online at http://www.learnmem.org/cgi/doi/10.1101//m.052274.120. fected, indicating that the treatment hampered reconsolidation specifically.

Episodic memory reconsolidation can also be enhanced. Of particular interest to our study is the finding that reconsolidation, like consolidation, benefits from sleep. If recently or remotely encoded episodic memories are reactivated before an extended period of sleep, the reactivated memories are protected against further forgetting (for reviews, see Stickgold and Walker 2007; Dudai 2012; Spiers and Bendor 2014). Moreover, even naps benefit reconsolidation. It has been shown that a short 40-min nap period facilitated the reconsolidation of remote memories, whereas recently encoded memories did not benefit at all (Klinzing et al. 2016). It is possible that, as is the case for consolidation, sleep is conducive to reconsolidation because it provides a state of reduced cognitive engagement and sensory input (Hasselmo 1999; Wixted 2004; Mednick et al. 2011; Dewar et al. 2012). If so, awake quiescence, which has this in common with sleep, should also be conducive to reconsolidation.

In the study reported here, we examined whether a period of awake quiescence following retrieval protects episodic memories from further forgetting by facilitating their reconsolidation. To this end, we combined a computerized item-location memory test with a modified version of our established consolidation paradigm, which compares between-subject effects of postencoding rest versus task engagement on recently encoded memories (e.g., Dewar et al. 2012). Item-location memory tests have previously been sensitive to the effects of postretrieval (reconsolidation) manipulations, including sleep (e.g., Klinzing et al. 2016) hence, subtle differences in memory scores can be recorded. Figure 1 provides an overview of the procedure. Sixty young adults (mean age $=$ $21.47 \mathrm{yr}, \mathrm{SD}=1.79 \mathrm{yr} ; 26 \mathrm{M}: 34 \mathrm{~F}$ ) were sequentially presented photos of 60 everyday items in unique locations on a 22-in touchscreen computer monitor. Immediately after each object's presentation, participants were asked to recall the object's location

C 2021 Craig et al. This article is distributed exclusively by Cold Spring Harbor Laboratory Press for the first 12 months after the full-issue publication date (see http://learnmem.cshlp.org/site/misc/terms.xhtml). After 12 months, it is available under a Creative Commons License (Attribution-NonCommercial 4.0 International), as described at http://creativecommons.org/licenses/by-nc/4.0\%. 

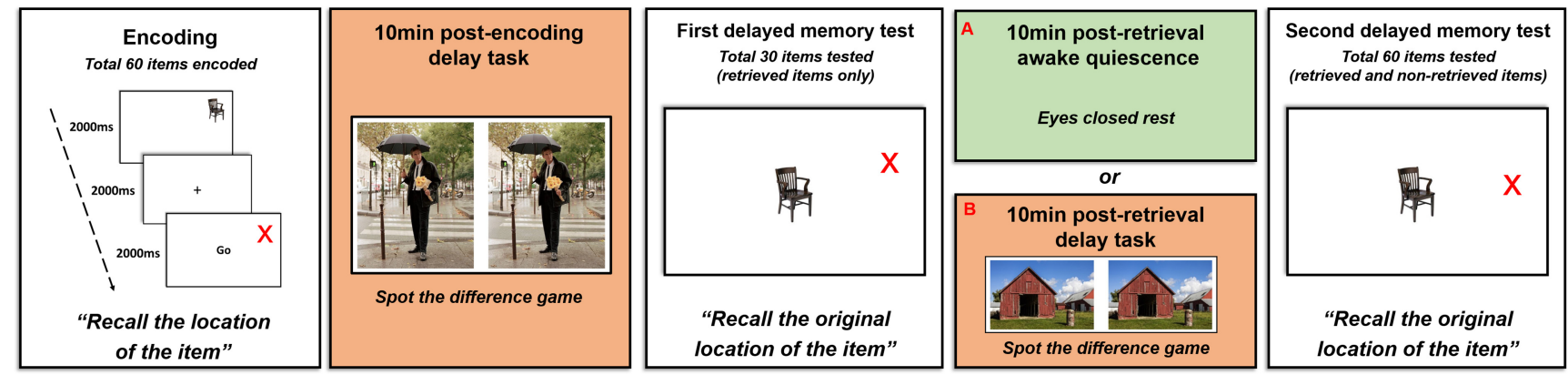

Figure 1. Experimental paradigm. Participants were presented 60 photos of unique everyday items from the Mnemonic Similarity Task (e.g., Stark et al. 2013) in unique locations on a computer screen. They then experienced $10 \mathrm{~min}$ of a postencoding delay task (a spot-the-difference game). Memory for the location of half of the encoded items $(N=30)$ was then probed via a first delayed recall test (via touchscreen response), before participants completed one of two postretrieval delay periods, each of which was $10 \mathrm{~min}$ in duration: awake quiescence $(N=30)(A)$, or an engaging perceptual task (a further spot-the-difference game comprising different stimuli to the earlier one) $(N=30)(B)$. In the subsequent second delayed recall test, participants' memory for the location of all the retrieved and nonretrieved items was probed $(N=60)$ (via touchscreen response). The experimental procedure took place in a single session.

via a touchscreen response as part of a "short-term spatial memory test" (encoding). They were unaware that they would perform subsequent long-term memory tests pertaining to the locations of these items. Location memory for half $(\mathrm{N}=30)$ of the encoded items ("retrieved items") was probed in a first delayed recall test that occurred after a 10-min delay filled with a visual spot-the-difference game (Dewar et al. 2012). There was no overlap between encoded items and spot-the-difference game stimuli. The first delayed recall test was followed by one of two postretrieval 10-min delay periods: (1) awake quiescence (quiet resting under strict conditions of minimal sensory input in a dimly lit room; $\mathrm{N}$ $=30$ participants), or (2) a further filler task (a spot-the-difference game comprising different stimuli to earlier; $\mathrm{N}=30$ participants) (Dewar et al. 2012). Memory for the location of all 60 encoded items was then probed via a second delayed recall test. This test included the 30 items that were probed during the first delayed recall test (retrieved items) and the 30 control items that were not probed during the first delayed recall test (nonretrieved items). Our key measure was the distance of error (in centimeters) between the initially presented locations of the everyday objects during encoding, and the recalled location during the first and second delayed recall tests. We also recorded the time that participants took to respond as well as confidence ratings during encoding and the first and second delayed recall tests. Analyzes were performed using SPSS 19 using ANOVAs, RM ANOVAs. and follow up $t$-tests that were used to investigate possible between-group differences. See the Supplemental Materials for detailed methods.

Given that our manipulation occurred during the postretrieval delay, we expected groups to be matched in their encoding, postencoding delay task, and first delayed memory test. Crucially, if postretrieval awake quiescence is conducive to episodic memory reconsolidation, then those who experience awake quiescence after the first delayed recall test should demonstrate less forgetting of "retrieved" items (smaller distances of error scores) in the second delayed recall test relative to those who experience the filler task after the first delayed recall test. Given that "control" items were not retrieved during the first delayed recall test immediately prior to our experimental manipulation (postretrieval quiescence vs. task), we predicted that memory (distance of error scores) for control items should be matched between groups in the second delayed recall test.

Data from two participants (perceptual task group) were lost due to technical issues. Thus, the following analyzes report data from 58 participants (quiescence group: $\mathrm{N}=30$, perceptual task group: $\mathrm{N}=28$ ). The two groups were well matched in their backgrounds and performance of the postencoding delay task (spot-the-difference game) (see the Supplemental Material). Moreover, as expected, the two groups were well matched in all memory measures occurring prior to our experimental manipulation. Specifically, we found no significant main effect of group in the mean distance of error (in centimeters) during (1) encoding of the items (quiescence: mean $=1.84 \mathrm{~cm}, \mathrm{SD}=0.57$; perceptual task: mean $=2.00 \mathrm{~cm}, \mathrm{SD}=0.47 ; \quad F_{(1,56)}=1.303, \quad P=.259, \quad \eta_{\mathrm{p}}^{2}=$ $0.023)$, (2) the first delayed recall test of the 30 "retrieved" items (quiescence: mean $=13.36 \mathrm{~cm}, \mathrm{SD}=3.37$; perceptual task: mean $=$ $\left.14.17 \mathrm{~cm}, \mathrm{SD}=3.67 ; F_{(1,56)}=0.775, P=0.383, \eta_{\mathrm{p}}^{2}=0.014\right)$, or $(3)$ the response times and confidence ratings in the first delayed recall test (see the Supplemental Material).

The second delayed recall test was completed immediately following our experimental manipulation, where participants experienced 10 min of either (1) awake quiescence ( $N=30$ participants), or (2) ongoing sensory input and cognitive engagement via an unrelated perceptual task (a different spot-the-difference game; Dewar et al. 2012) ( $\mathrm{N}=30$ participants). This delayed recall test included the 30 items that were probed during the first delayed recall test (retrieved items) and the 30 control items that were not probed during the first delayed recall test (nonretrieved items). A RM ANOVA comprised of within-subject factor item type (retrieved vs. nonretrieved) and between-subject factor group (awake quiescence vs. perceptual task) revealed no significant main effect of group in distance of error scores (in centimeters; $F_{(1,56)}=0.686$, $P=0.411, \eta_{\rho}^{2}=0.012$ ). We did, however, find a significant main effect of item type (retrieved vs. nonretrieved; $F_{(1,56)}=14.138, P<$ $0.001, \eta_{\rho}^{2}=0.202$ ) because, overall, the distance of error (in centimeters) was larger for nonretrieved (mean $=14.56 \mathrm{~cm}, \mathrm{SD}=3.49$ $\mathrm{cm})$ than retrieved $($ mean $=13.36 \mathrm{~cm}, \mathrm{SD}=3.38 \mathrm{~cm}$ ) items. There was a significant interaction between group (awake quiescence vs. perceptual task) and item type (retrieved vs. nonretrieved; $\left.F_{(1,56)}=4.561, P=0.037, \eta_{\mathrm{p}}^{2}=0.075\right)$.

Paired $t$-tests revealed that the above interaction emerged because, in the perceptual task group, the distance of error was significantly larger for nonretrieved (mean $=15.27, \mathrm{SD}=3.32 \mathrm{~cm}$ ) than retrieved $($ mean $=13.37 \mathrm{~cm}, S D=3.64 \mathrm{~cm})$ items $\left(t_{(27)}=\right.$ $-5.05, P<0.001$; see Fig. 2). This significant finding survived Bonferroni correction for multiple comparisons ( $\alpha$ level of 0.050 / four comparisons $=$ corrected $\alpha$ level of 0.013). This was not the case in the quiescence group, where no significant item type difference was observed (retrieved: mean $=13.36 \mathrm{~cm}, \mathrm{SD}=3.49 \mathrm{~cm}$; nonretrieved: mean $\left.=13.89 \mathrm{~cm}, \mathrm{SD}=3.26 \mathrm{~cm} ; t_{(29)}=-1.018, P=0.317\right)$. Independent $t$-tests revealed no effect of delay group in the distance of error for retrieved items (quiescence: mean $=13.36 \mathrm{~cm}$, $\mathrm{SD}=3.49 \mathrm{~cm}$; task: mean $=13.37, \mathrm{SD}=3.33 ; t_{(56)}=-0.008, P=$ 


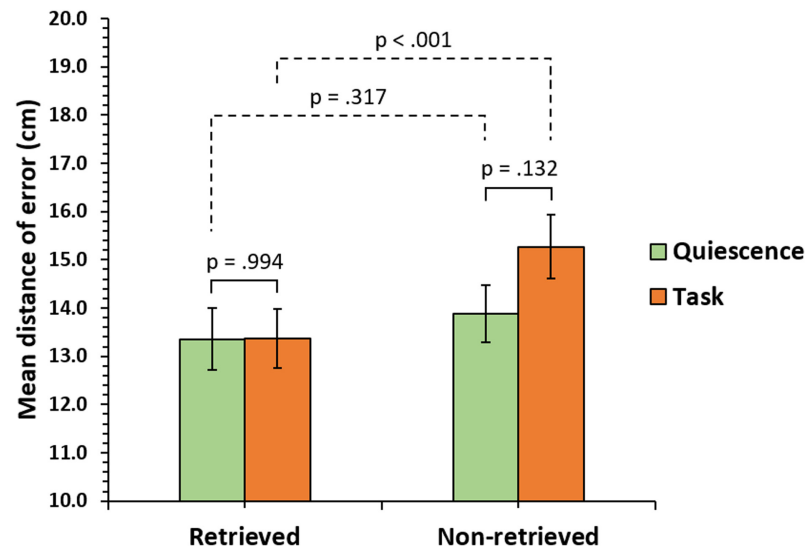

Figure 2. Memory performance in the second delayed recall test. Mean distance of error (in centimeters) in the second delayed recall test for items that were and were not "retrieved," that is, probed, during the first delayed recall test. The data for both the quiescence and task groups are shown. Distance of error refers to the deviation in location from the initially presented location of each item. Error bars show the standard error of the mean. Full lines show between-group comparisons (quiescence vs. task) of distance of error (in centimeters) scores, and dashed lines show withinsubject comparisons (retrieved vs. nonretrieved).

0.994 ) or nonretrieved items (quiescence: mean $=13.88 \mathrm{~cm}, \mathrm{SD}=$ $3.26 \mathrm{~cm}$; task: mean $=15.27 \mathrm{~cm}, \mathrm{SD}=3.64 \mathrm{~cm} ; t_{(56)}=-1.530, P=$ 0.132 ). The groups were matched in their second delayed recall test response times and confidence ratings (see the Supplemental Material).

Our data reveal comparable delayed recall performance for recently retrieved item locations in participants who rested quietly after retrieval and those who played a spot-the-difference game after retrieval (see the "retrieved" data in Fig. 2). Although these findings could suggest that awake quiescence had no effect on the reconsolidation of item-location memories, methodological shortfalls (discussed below) render this conclusion unlikely. However, we did find an unforeseen beneficial effect of quiescence for nonretrieved versus retrieved photo locations: Those who experienced the spot-the-difference game in the second delay phase demonstrated significant forgetting of nonretrieved items relative to retrieved items, whereas those who experienced awake quiescence in the second delay phase did not demonstrate such forgetting (see the "nonretrieved" data in Fig. 2). We discuss these two key findings in turn.

Why did we not observe any effects of postretrieval awake quiescence on reconsolidation in our study? One possibility is that, unlike sleep, awake quiescence simply does not benefit reconsolidation. A much more likely possibility is that methodological shortfalls mean that our study did not in fact probe reconsolidation. This may be true for a few reasons. First, sometimes retrieval is not sufficient to reactivate memories and reintroduce them into a labile state (e.g., Cammarota et al. 2004; Forcato et al. 2009). In fact, the protective effect of retrieval against forgetting is well documented, even over a delay of a few minutes (Karpicke and Roediger 2008; Roediger and Butler 2011), possibly because it provides a "fast route to consolidation" of new memories (Antony et al. 2017). Notwithstanding the power of retrieval to boost memory, the research discussed earlier shows that memories reactivated via retrieval can (still) benefit from postretrieval sleep. Do these studies differ from our own with regards to memory reactivation? Possibly, reactivation in our study occurred after a short delay (10 $\mathrm{min})$. It is possible that retrieval was so effective at protecting against forgetting in our study because it occurred shortly after encoding and during the initial consolidation of memory traces.
Indeed, studies investigating the role of different treatments (e.g., sleep, pharmaceuticals) in reconsolidation typically require participants to retrieve previously encoded memories after a much longer delay period (several hours to days). After lengthy delays such as those, encoded memories would be expected to have completed initial consolidation, or at least be much further along in the consolidation process than in our study. The 10-min delay in our study might simply have been too short for memories to consolidate sufficiently to be relabilized again. As a result, retrieval might have simply strengthened memories against forgetting and did not sufficiently return them to a labile state. These methodological shortfalls mean that our study is unlikely to have probed reconsolidation effectively. Therefore, we cannot conclude whether postretrieval awake quiescence benefits the reconsolidation of episodic memories.

How can we explain the unforeseen finding that "postretrieval" awake quiescence protected against subsequent forgetting for nonretrieved (control) items, which were not probed in the first delayed recall test? Our data reveal an effect of delayed rest that was on par with the overall beneficial effect of retrieval-mediated memory reactivation (i.e., the well-established effect of retrieval practice; see above). The findings suggest that in the task group, the lack of reactivation for nonretrieved items in the first delayed recall test negatively affected these memories. However, in the quiescence group, this lack of reactivation was offset by delayed rest, which seemingly had a similarly beneficial effect on nonretrieved memories. It is unlikely that this benefit of delayed rest can be explained by intentional rehearsal. The occurrence of quiet rest after a 10-min filled delay, as opposed to immediately after encoding, makes it unlikely that participants rehearsed the nonretrieved items during the rest period because they would require explicit knowledge that they had been tested on only half of the encoded items in the first delayed recall test and spend their time rehearsing what they could recall from the subset of items that were not tested. While this does not rule out rehearsal completely, our findings reinforce recent data (e.g., Dewar et al. 2014) showing that rest-related enhancements in memory cannot simply be explained by intentional rehearsal. A consolidation account can provide a more likely explanation.

Previous research on the beneficial effect of awake quiescence on memory has focused on immediate rest (i.e., rest periods occurring immediately following encoding) (Dewar et al. 2007, 2012, 2014; Craig et al. 2015, 2016; Mercer 2015; Brokaw et al. 2016; Craig and Dewar 2018; Humiston and Wamsley 2018; Sacripante et al. 2019). The rationale for this focus has been that new memories are most labile upon their initial formation (Mednick et al. 2011; Wixted and Cai 2013), and thus, supportive or disruptive interventions applied during this time should be most effective. The findings of the current study suggest that the effect of awake quiescence is sufficiently powerful to influence new memories even 10-20 min after encoding, that is, when memories have-presumably-benefited from some initial consolidation and are no longer highly labile. Moreover, they indicate that awake quiescence can support the consolidation of new memories even if the awake quiescence occurs after a period of task engagement rather than immediately after encoding. The latter hypothesis resonates with the view that consolidation is an opportunistic process (Mednick et al. 2011) and raises interesting questions about how late the onset of rest would need to be for it to no longer facilitate the consolidation of new memories. This remains to be established, but we predict that the benefit of quiescence should diminish in accordance with increasing delay in the onset of the rest period as memories are increasingly stabilized through consolidation that occurs independently of that during intentional rest. Investigation of this question may provide insights into the initial timeline of episodic memory consolidation, which is characterized poorly. Thus, more 
work is required to establish whether a relationship exists between the precision of item location memory and the time lag between initial encoding and postencoding quiescence.

In summary, methodological shortfalls mean that we failed to probe the possible effect of awake quiescence on episodic memory reconsolidation. Nonetheless, we unexpectedly revealed that awake quiescence following encoding reduces forgetting, even when experienced at a delayed point in time and following a period of task engagement. This finding indicates that awake quiescence need not commence immediately following encoding to benefit memory consolidation, at least for object location memories. Further investigation and independent replication of this effect are required to better understand the underlying mechanisms and implications of our unexpected finding.

\section{References}

Agren T. 2014. Human reconsolidation: a reactivation and update. Brain Res Bull 105: 70-82. doi:10.1016/j.brainresbull.2013.12.010

Antony JW, Ferreira CS, Norman KA, Wimber M. 2017. Retrieval as a fast route to memory consolidation. Trends Cogn Sci 21: 573-576. doi:10 $.1016 /$ j.tics.2017.05.001

Brokaw K, Tishler W, Manceor S, Hamilton K, Gaulden A, Parr E, Wamsley EJ. 2016. Resting state EEG correlates of memory consolidation. Neurobiol Learn Mem 130: 17-25. doi:10.1016/j.nlm .2016 .01 .008

Cahill L, Prins B, Weber M, McGaugh JL. 1994. $\beta$-Adrenergic activation and memory for emotional events. Lett to Nat 371: 702-704. doi:10.1038/ $371702 \mathrm{a} 0$

Cammarota M, Bevilaqua LRM, Medina JH, Izquierdo I. 2004. Retrieval does not induce reconsolidation of inhibitory avoidance memory. Learn Mem 11: $572-578$. doi:10.1101/lm.76804

Clemens Z, Fabó D, Halász P. 2005. Overnight verbal memory retention correlates with the number of sleep spindles. Neuroscience 132: 529-535. doi:10.1016/j.neuroscience.2005.01.011

Craig M, Dewar M. 2018. Rest-related consolidation protects the fine detail of new memories. Sci Rep 8: 1-9. doi:10.1038/s41598-017-17765-5

Craig M, Dewar M, Della Sala S, Wolbers T. 2015. Rest boosts the long-term retention of spatial associative and temporal order information. Hippocampus 25: 1017-1027. doi:10.1002/hipo.22424

Craig M, Dewar M, Harris MA, Della Sala S, Wolbers T. 2016. Wakeful rest promotes the integration of spatial memories into accurate cognitive maps. Hippocampus 26: 185-193. doi:10.1002/hipo.22502

Craig M, Wolbers T, Strickland S, Achtzehn J, Dewar M. 2019. Rapid improvement of cognitive maps in the awake state. Hippocampus 29: 862-868. doi:10.1002/hipo.23081

Debiec JD, Ledoux JE. 2004. Disruption of reconsolidation but not consolidation of auditory feat conditioning by noradrenergic blockade in the amygdala. Neuroscience 129: 267-272. doi:10.1016/j .neuroscience.2004.08.018

Deeprose C, Zhang S, Dejong H, Dalgleish T, Holmes EA. 2012. Imagery in the aftermath of viewing a traumatic film: using cognitive tasks to modulate the development of involuntary memory. J Behav Ther Exp Psychiatry 43: 758-764. doi:10.1016/j.jbtep.2011.10.008

Dewar M, Cowan N, Della Sala S. 2007. Forgetting due to retroactive interference: a fusion of Müller and Pilzecker's (1900) early insights into everyday forgetting and recent research on anterograde amnesia. Cortex 43: 616-634. doi:10.1016/S0010-9452(08)70492-1

Dewar M, Alber J, Butler C, Cowan N, Della Sala S. 2012. Brief wakeful resting boosts new memories over the long term. Psychol Sci 23: 955-960. doi:10 $.1177 / 0956797612441220$

Dewar M, Alber J, Cowan N, Della Sala S. 2014. Boosting long-term memory via wakeful rest: intentional rehearsal is not necessary, consolidation is sufficient. PLoS One 9: e109542. doi:10.1371/journal.pone.0109542

Dudai Y. 2004. The neurobiology of consolidations, or, how stable is the engram? Annu Rev Psychol 55: 51-86. doi:10.1146/annurev.psych.55 .090902 .142050

Dudai Y. 2012. The restless engram: consolidations never end. Annu Rev Neurosci 35: 227-247. doi:10.1146/annurev-neuro-062111-150500

Dudai Y, Eisenberg M. 2004. Rites of passage of the engram: reconsolidation and the lingering consolidation hypothesis. Neuron 44: 93-100. doi:10 .1016/j.neuron.2004.09.003

Ferrara M, Iaria G, Tempesta D, Curcio G, Moroni F, Marzano C, De Gennaro L, Pacitti C. 2008. Sleep to find your way: the role of sleep in the consolidation of memory for navigation in humans. Hippocampus 18: 844-851. doi:10.1002/hipo.20444

Forcato C, Argibay PF, Pedreira ME, Maldonado H. 2009. Human reconsolidation does not always occur when a memory is retrieved: the relevance of the reminder structure. Neurobiol Learn Mem 91: 50-57. doi:10.1016/j.nlm.2008.09.011

Gaskell MG, Warker J, Lindsay S, Frost R, Guest J, Snowdon R, Stackhouse A. 2014. Sleep Underpins the Plasticity of Language Production. Psychol Sci 25: $1457-1465$. doi: $10.1177 / 0956797614535937$

Hagenaars MA, Holmes EA, Klaassen F, Elzinga B. 2017. Tetris and Word games lead to fewer intrusive memories when applied several days after analogue trauma. Eur J Psychotraumatol 8: 1386959. doi:10.1080/ 20008198.2017.1386959

Hasselmo ME. 1999. Neuromodulation: acetylcholine and memory consolidation. Trends Cogn. Sci. 3: 351-359. doi:10.1016/S1364-6613 (99)01365-0

Humiston GB, Wamsley EJ. 2018. A brief period of eyes-closed rest enhances motor skill consolidation. Neurobiol Learn Mem 155: 1-6. doi:10.1016/j .nlm.2018.06.002

Hupbach A, Gomez R, Hardt O, Nadel L. 2007. Reconsolidation of episodic memories: a subtle reminder triggers integration of new information. Learn Mem 14: 47-53. doi:10.1101/lm.365707

James EL, Bonsall MB, Hoppitt L, Tunbridge EM, Geddes JR, Milton AL, Holmes EA. 2015. Computer game play reduces intrusive memories of experimental trauma via reconsolidation-update mechanisms. Psychol Sci 26: $1201-1215$. doi: $10.1177 / 0956797615583071$

Karpicke JD, Roediger HL. 2008. The critical importance of retrieval for learning. Science 319: 966-968. doi:10.1126/science.1152408

Klinzing JG, Rasch B, Born J, Diekelmann S. 2016. Sleep's role in the reconsolidation of declarative memories. Neurobiol Learn Mem 136: 166-173. doi:10.1016/j.nlm.2016.10.004

Kroes MCW, Tendolkar I, Van Wingen GA, Van Waarde JA, Strange BA, Fernández G. 2014. An electroconvulsive therapy procedure impairs reconsolidation of episodic memories in humans. Nat Neurosci 17: 204-206. doi:10.1038/nn.3609

Lahl O, Wispel C, Willigens B, Pietrowsky R. 2008. An ultra short episode of sleep is sufficient to promote declarative memory performance. J Sleep Res 17: 3-10. doi:10.1111/j.1365-2869.2008.00622.x

Loftus EF. 2005. Planting misinformation in the human mind : a 30-year investigation of the malleability of memory. Learn Mem 12: 361-366. doi:10.1101/lm.94705

McKenzie S, Eichenbaum H. 2011. Consolidation and reconsolidation: two lives of memories? Neuron 71: 224-233. doi:10.1016/j.neuron.2011.06 .037

Mednick SC, Cai DJ, Shuman T, Anagnostaras S, Wixted JT. 2011. An opportunistic theory of cellular and systems consolidation. Trends Neurosci 34: 504-514. doi:10.1016/j.tins.2011.06.003

Mercer T. 2015. Wakeful rest alleviates interference-based forgetting. Memory 23: 127-137. doi:10.1080/09658211.2013.872279

Przybyslawski J, Sara SJ. 1997. Reconsolidation of memory after its reactivation. Behav Brain Res 84: 241-246. doi:10.1016/S0166-4328(96) 00153-2

Rodriguez WA, Phillips MY, Rodriguez SB, Martinez JL. 1993. Cocaine administration prior to reactivation facilitates later acquisition of an avoidance response in rats. Psychopharmacology (Berl) 112: 366-370. doi:10.1007/BF02244934

Roediger HL, Butler AC. 2011. The critical role of retrieval practice in longterm retention. Trends Cogn Sci 15: 20-27. doi:10.1016/j.tics.2010.09.003

Sacripante R, McIntosh RD, Della Sala S. 2019. Benefit of wakeful resting on gist and peripheral memory retrieval in healthy younger and older adults. Neurosci Lett 705: 27-32. doi:10.1016/j.neulet.2019.04.026

Schwabe L, Nader K, Pruessner JC. 2014. Reconsolidation of human memory: brain mechanisms and clinical relevance. Biol Psychiatry 76: 274-280. doi:10.1016/j.biopsych.2014.03.008

Spiers HJ, Bendor D. 2014. Enhance, delete, incept: manipulating hippocampus-dependent memories. Brain Res Bull 105: 2-7. doi:10 .1016/j.brainresbull.2013.12.011

Stark S, Yassa M, Lacy J, Stark C. 2013. A task to assess behavioral pattern separation (BPS) in humans: data from healthy aging and mild cognitive impairment. Neuropsychologia 51: 2442-2449. doi:10.1016/j .neuropsychologia.2012.12.014

Stickgold R, Walker MP. 2007. Sleep-dependent memory consolidation and reconsolidation. Sleep Med 8: 331-343. doi:10.1016/j.sleep.2007.03.011

Wamsley EJ, Tucker MA, Payne JD, Stickgold R. 2010. A brief nap is beneficial for human route-learning: the role of navigation experience and EEG spectral power. Learn Mem 17: 332-336. doi:10.1101/lm.1828310

Wichert S, Wolf OT, Schwabe L. 2011. Reactivation, interference, and reconsolidation: are recent and remote memories likewise susceptible? Behav Neurosci 125: 699-704. doi:10.1037/a0025235

Wixted JT. 2004. The psychology and neuroscience of forgetting. Annu Rev Psychol 55: 235-269. doi:10.1146/annurev.psych.55.090902.141555

Wixted JT, Cai DJ. 2013. Memory consolidation. Oxford Handb Cogn Neurosci 436-455. doi:10.1093/oxfordhb/9780199988693.013.0021

Received July 3, 2020; accepted in revised form October 27, 2020. 


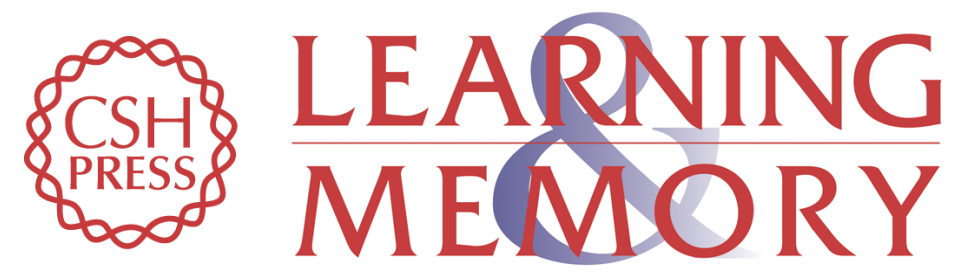

\section{A study on episodic memory reconsolidation that tells us more about consolidation}

Michael Craig, Christopher Knowles, Stephanie Hill, et al.

Learn. Mem. 2021, 28:

Access the most recent version at doi:10.1101/Im.052274.120

\section{Supplemental http://learnmem.cshlp.org/content/suppl/2021/01/13/28.2.30.DC1 Material}

References This article cites 46 articles, 5 of which can be accessed free at: http://learnmem.cshlp.org/content/28/2/30.full.html\#ref-list-1

Creative This article is distributed exclusively by Cold Spring Harbor Laboratory Press for the Commons first 12 months after the full-issue publication date (see

License http://learnmem.cshlp.org/site/misc/terms.xhtml). After 12 months, it is available under a Creative Commons License (Attribution-NonCommercial 4.0 International), as described at http://creativecommons.org/licenses/by-nc/4.0/.

Email Alerting Receive free email alerts when new articles cite this article - sign up in the box at the Service top right corner of the article or click here. 